\title{
A controlled trial of parent initiated and conventional preschool health surveillance using personal child health records
}

\author{
John Dearlove, Su Illingworth
}

\begin{abstract}
Objectives-A comparison of parent initiated preschool surveillance, using personal child health records, with the then current system of child health surveillance using child health records.

Design-Prospective, controlled trial with randomisation of five general practices into two groups.

Setting-Five general practices, a well baby clinic, and an orthoptic clinic at Yeovil District Hospital.

Subjects- 538 babies born between 1 April 1992 and 1 November 1994, from within the five general practices.

Main outcome measures-The number of screenable abnormalities in the two groups that were missed in the first 3 years of a baby's life.

Results-163 babies from the parent initiated preschool surveillance group and 107 from the conventional group completed the study. Although all the mothers from the parent initiated preschool surveillance group understood the concept of parent initiated surveillance, 117 stated their health visitor had made their appointments. Only 45 mothers made their own appointments. The abnormality rates were: 12 of 163 and eight of 107 at 1 year and nine of 163 and six of 107 at 3 years. No medically important conditions were missed. Most mothers did not want to make their own appointments because it was inconvenient. The system was unpopular with health visitors.

Conclusion-Parent initiated preschool surveillance is as safe as the current system. Implementing the idea involved a small change in work practice and a large change conceptually for some of the primary health care team. It was not adopted in east Somerset. (Arch Dis Child 1999;80:507-510)
\end{abstract}

Keywords: controlled trial; personal child health records; surveillance; parent initiated preschool surveillance

Community Health,

Trust, Summerlands

Hospital, Preston

Road, Yeovil,

Somerset,

BA20 2BX, UK

S Illingworth

Correspondence to: Dr Dearlove.

Accepted 18 December 1998 feasibility of parent initiated surveillance. The parent initiated preschool child surveillance system means that, with the exception of immunisations, parents are responsible for arranging all their child's health surveillance procedures. In Somerset these procedures include the routine 6 week baby examination, the detection of abnormalities of growth, congenital heart problems, hip instability, and undescended testes, and health visitor hearing and orthoptic checks.

Parent initiated preschool surveillance has the advantage of allowing parents to make appointments at their own convenience and to pick and choose from the surveillance procedures that they feel are useful. It also encourages parents to take greater responsibility for their baby's routine health care.

We designed our study to determine whether parent initiated preschool surveillance was as safe as a conventional system where appointments were made for the child and parents.

Subjects and methods

We used the personal child health records recommended by the Royal College of Paediatrics and Child Health but adapted in the following manner: two pages were included at the beginning of the record, the first defining the screening procedures recommended by the Somerset Health Authority and when to do them. Parents were told that these were the recommendations of the Somerset Health Authority but that each parent was free to choose whether they wanted a particular test and should then contact their health visitor or family practitioner to make an appointment. On page two there was considerable emphasis on parents being in charge of their children's surveillance by making appointments themselves, getting health personnel to use their personal child health record, and writing in the record themselves.

Five general practices were involved. Each was randomly allocated to the parent initiated preschool surveillance scheme (and so used the adapted personal child health records) or to the routine appointment system and child health record booklet. We discussed with the health visitors about randomly allocating the babies to the parent initiated preschool surveillance group, or control group, within each practice. However, we felt that it was too difficult to allocate families randomly within individual general practices. After 18 months the practices using the parent initiated preschool surveillance scheme reverted to the old system of 


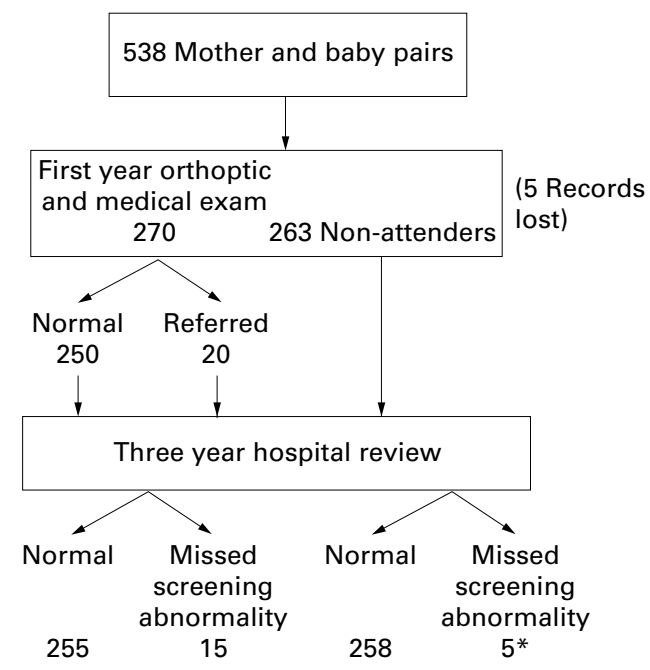

Figure 1 Outcomes of our study. ${ }^{*} \chi^{2}=4.9$ (not significant).

appointments only. The practices using the old child health records system (including the regular appointment system) then started using the scheme involving parent initiated preschool surveillance and personal child health records.

At the beginning of our study we held detailed workshops with the health visitors of the five practices, exploring the practicalities of parents initiating contacts with the primary health care team, rather than the reverse, as well as discussing what to do if mothers in the parent initiated preschool surveillance scheme did not turn up, or were felt to be neglectful. We explained the aims of our study to the mothers either antenatally or at the first home visit. Ethical approval had been given and a six month pilot study published, as a non-peer reviewed abstract.

When each child was 1 year old, their parents were sent appointments to two specially arranged examinations: (1) an orthoptic clinic to check that their eye screening tests had been carried out and that no screenable orthoptic abnormalities that should have been detected in their 1st year surveillance programme had been missed; and (2) a specific community well baby clinic, where a structured interview,

Table 1 Profile of the 1st birthday clinic attendance $(n=304)$

\begin{tabular}{lcc}
\hline & $\begin{array}{l}\text { Parent initiated } \\
\text { screening }\end{array}$ & $\begin{array}{l}\text { Child health } \\
\text { record }\end{array}$ \\
\hline Number of mothers and babies attending 1st year examination & 163 & 107 \\
Forgot to bring record & 5 & 4 \\
Lost record & 8 & 9 \\
Wrong record, defaced, or no record & 6 & 2 \\
Non-attenders & 116 & 118 \\
\hline
\end{tabular}

One mother refused to come to the examination.

Table 2 Missed screening abnormalities at 1 year examination

\begin{tabular}{lll}
\hline & $\begin{array}{l}\text { Parent initiated } \\
\text { screening }(n=163)\end{array}$ & $\begin{array}{l}\text { Child health } \\
\text { record }(n=107)\end{array}$ \\
\hline $\begin{array}{l}\text { Benign murmurs } \\
\text { Pulmonary stenosis }\end{array}$ & 5 & - \\
$\begin{array}{l}\text { Abnormal echocardiogram } \\
\text { Possible strabismus }\end{array}$ & - & 1 (no operation) \\
$\begin{array}{l}\text { Possible cataract } \\
\text { Hearing problems }\end{array}$ & $4(1$ real $)$ & 3 (no operation) \\
Failure to thrive & 1 & 1 (nost notes, 2 normal) \\
Number of referred babies & 2 & 2 \\
\hline
\end{tabular}

Table 3 Missed screening abnormalities at 36 months

\begin{tabular}{lll}
\hline & $\begin{array}{l}\text { Parent initiated } \\
\text { screening } \\
(n=163)\end{array}$ & $\begin{array}{l}\text { Child health } \\
\text { record } \\
(n=107)\end{array}$ \\
\hline $\begin{array}{l}\text { Moderate learning disability } \\
\text { Benign murmur }\end{array}$ & 1 & - \\
Eyes & 3 (normal) & - \\
Ear, nose, and throat & 3 & 2 \\
Urinary tract infection & 1 & - \\
Failure to thrive & - & 1 \\
Personal syndrome & - & 1 \\
Number of referred children & 9 & 6 \\
\hline
\end{tabular}

examination, and screening developmental assessment occurred. Again, the aim was to detect any abnormality that should have been detected by the screening programme. This was performed by one of the authors (JD).

A referral at these two examinations was defined as an abnormality for which the baby should have been screened but which had been missed during the 1 st year surveillance, which was sufficient to generate a referral elsewhere.

In addition, we scrutinised and noted the number of entries in the personal child health records, and child health record booklets. The parents had also been sent two questionnaires, one about their satisfaction with whichever surveillance system they were using and, if they were using parent initiated preschool surveillance, specific questions about the first two pages of their personal child health record, and their understanding of parent initiated surveillance. They were asked whether either method of child surveillance had changed their behaviour and to give specific examples, which were checked later in the interview.

We cross checked the accuracy of the immunisation data and the vision and hearing screening tests in their parent held records against the child health surveillance computer database. We also checked the child protection register.

Finally, about three years later, we read their hospital notes, to ensure that no 1 st year screening abnormalities had been missed even in the 1 year parent held record clinic. A 3rd year screening abnormality was defined as one which should have been detected over the previous three years by the surveillance programme but had been missed (in JD's judgment) and then discovered opportunistically and referred. This was in case an abnormality was missed, or because the child missed the 1st year examinations. The children were not re-examined at this point.

\section{Results}

There were 538 mother/baby pairs in our prospective study. A summary of the outcomes of the children's 1st birthday examinations, and their 3rd year medical record review are shown in fig 1 .

Only 304 mothers brought their babies for their 1 st year examinations (table 1). Tables 2 and 3 show the number of screening abnormalities that were discovered during this examination and after the age of 36 months, respectively. Twelve of the 163 children in the parent initiated system had a screening abnormality that had been missed during their surveillance 
Table 4 A comparison of the understanding of mothers using the parent initiated surveillance system with the conventional child health record

\begin{tabular}{|c|c|c|}
\hline & $\begin{array}{l}\text { Parent initiated } \\
\text { surveillance }(n=163)\end{array}$ & $\begin{array}{l}\text { Child health } \\
\text { record }(n=107)\end{array}$ \\
\hline Mothers who understood the concept of parent initiated surveillance & $118(71 \%)$ & $3^{\star}(3 \%)$ \\
\hline Mothers who felt that they had made their own appointments & $57(34 \%)$ & $21(20 \%)$ \\
\hline Mothers who understood parent initiated surveillance, and made their own appointments & $45(28 \%)$ & $0(0 \%)$ \\
\hline Mothers who learnt something new from their baby's surveillance record & $30(18 \%)$ & $14(13 \%)$ \\
\hline Mothers whose behaviour had changed because of what they had read in their baby's record & $21(12 \%)$ & $5(4 \%)$ \\
\hline
\end{tabular}

`These three mothers had been part of the parent initiated surveillance group initially.

Table 5 Profiles and outcomes for parents using parent initiated surveillance and personal child health records ( $n=163$ ) who understood parent initiated surveillance $(n=118$ of 163$)$ and made their own appointments compared with those parents who understood parent initiated surveillance but did not make their own appointments

\begin{tabular}{lll}
\hline & $\begin{array}{l}\text { Number of babies whose mothers made } \\
\text { their own appointments }(n=45)\end{array}$ & $\begin{array}{l}\text { Number of babies whose mothers did not } \\
\text { make their own appointments }(n=45)\end{array}$ \\
\hline Lone parent & 5 & 8 \\
First child & 19 & 37 \\
Screening abnormality missed at 1 year & 2 & 6 \\
Screening abnormality missed at 3 years & 2 & 5 \\
Mean number (range) of parental entries in personal child health record & $8(0-40)$ & $7.5(0-77)$ \\
Mean number (range) of health visitor entries in personal child health records & $14(2-45)$ & $0.6(0-34)$ \\
Mean number of social worker entries in personal child health records & 0 & 0 \\
Mean number (range) of general practitioner entries in personal child health records & $2(0-12)$ & $2(0-9)$ \\
Mean number (range) of other entries & $0.25(0-5)$ & $0.33(0-8)$ \\
Number of parents who would have liked a parent initiated surveillance scheme, & 16 & 20 \\
involving making their own appointments & 16 & \\
\hline
\end{tabular}

^Other entries include those made by other NHS, nursery, and education department staff.

programme, but picked up during their examination at the age of 1 year, compared with eight of the 107 children in the conventional system.

Similarly, nine more were discovered to have an abnormality that should have been picked up by their screening programme when their hospital record and child health record were compared after the age of 3 years. This is in contrast to six from the 107 babies in the conventional child health record group.

Table 4 compares mothers' understanding of parent initiated surveillance and whether their own behaviour had changed because of what they had to read. However, the core of parent initiated surveillance were the 45 mothers, from a possible 163, who made their own appointments. The profile and outcomes of this group of 45 are compared with the 70 mothers in the parent initiated surveillance group who did not make their own appointments. These are shown in table 5. Lone parents and primigravidas were proportionately represented in both samples of mothers (those who did or did not make their own appointments) and there was no increase in missed screening abnormalities in the group of mothers using parent initiated surveillance. We found no difference in the way the two groups used their personal child health record, as measured by the number of entries in each group's child health record or personal child health record. We were disappointed to see how little the records were used by everyone except health visitors and general practitioners. In addition, most mothers preferred not to make their own surveillance appointments, but we found no difference in the reasons given by mothers as to why they preferred to make their own appointments, or have them sent to them: both groups cited convenience.

Finally, we questioned whether the children who failed to attend for their 1st year examinations do badly in one or the other surveillance system? In general, the non-attenders had babies with fewer screening abnormalities than the more diligent mothers who kept their appointments, as shown in fig 1 . This could be the result of chance; or that absentee mothers used their common sense, and did not use the clinic unless they thought there was something wrong.

\section{Discussion}

In our prospective study of 163 families who used parent initiated surveillance, the 45 mothers who understood the concept of parents initiating their own appointments for their baby's surveillance procedures, and felt that they had done so, fared no better or worse than the 70 mothers who understood the concept, but had their appointments made for them. This was in terms of their baby's medical outcomes at 1 year of age, and probably also by the age of 3 years. One concern about parent initiated surveillance was that the most disadvantaged mothers might not be able to adapt to the new system. However, we were reassured at finding lone parents and irregular clinic attenders were not penalised by the new system in terms of their children's outcomes. Overt criticism was expressed by only one mother who considered parent initiated surveillance as primarily a cost cutting exercise rather than as an attempt to give parents freedom of choice. However, clinic attendance rates were very poor-only about half the sample size. This might be a reflection of the value that mothers placed on the two 1st year examinations, especially if they thought that their baby was well. In line with this view is that few important abnormalities were revealed when going through these babies' hospital notes, whether or not families attended their baby's 1st birthday examinations. The five health centres refer locally, and the nearest hospital is 35 miles away, so it is unlikely that major treatable abnormalities were assessed elsewhere. However, a large number of babies had trivial 
abnormalities that were not known to the parent, but were detected at one of the surveillance procedures. They would have been missed safely in a parent initiated system of surveillance, leaving the health visitor more time to deal with more worrying families. However there is little evidence that this happens if the primary care team are left to themselves, ${ }^{3}$ rather than being part of a specific study with defined roles. ${ }^{4}$ The most important person in getting parent initiated surveillance to work is not the parent, but the health visitor. With this in mind, a number of health visitor workshops were held, aimed at developing a fact sheet to enable those new to both parent initiated surveillance and to personal child health records to be able to use both systems effectively, and to discuss their personal views of the new system. This method has been advocated elsewhere. ${ }^{5}$ The final result was circulated to all the health visitors involved in our study. Despite this, it was clear from what parents said at their baby's 1st birthday examination that parents' appointments were being made for them, often along the lines of: "Our baby clinic is on Tuesday afternoons. Now, you are in the special group of parents who make their own appointments for their babies, so when would you like to come?" This had two results: it reaffirmed who was actually in charge $^{6}$ and temporarily combined all the 1 st year surveillance procedures, effectively excluding any parental choice. Given this sort of pressure, it was remarkable that 45 parents persisted, and after a year still felt that they were in control of their child's surveillance.

Although our study was not about the effectiveness of our 1 st year surveillance programme, it adds weight to the argument that only relatively trivial problems are uncovered by the current system. This is not a reason for abandoning all the procedures, but probably an opportunity for the primary health care team to look at more effective programmes, that have clear benefits to their paediatric patients ${ }^{7}$ and parents. The success of parental and professional partnerships is cited in specific areas of case management such as child disability, ${ }^{8}$ immunisation, ${ }^{9}$ and parenting programmes. ${ }^{10}$ However, a careful study of health visitors' case loads showed no consistent pattern to the delivery of preventative programmes designed to ameliorate the effects of disadvantage. ${ }^{11}$ In addition, difficulties of parent partnerships with professionals can be a blurring of theory and practice, ${ }^{12}{ }^{13}$ degenerating into a quagmire of paternalism, ${ }^{14}$ tokenism, ${ }^{15}$ and feminism. ${ }^{16}$ Consequently, alternative approaches have involved other mothers or non-professionals as advocates. ${ }^{17} 18$

It is also a reminder that changing the working habits of a group involves more than a nominal acceptance of change. Our study failed because the health workers did not believe in it $^{19}$ and because the hero innovator ${ }^{20}$ was made redundant during a management reorganisation. The result was that it was straightforward to monitor what was happening but very difficult to influence behaviour. If our study had been extended, it would have been beneficial to have had some executive structure in place ${ }^{21}$ to make sure that what was said to happen was actually happening, utilising the experiences of others. ${ }^{22}{ }^{23}$

As a way forward East Somerset NHS Trust is exploring shared budgets with local authority social services and education departments, focusing on young financially unsupported families, from conception to the child's 5th year.

In summary, parent initiated surveillance is easy to implement but it involves a considerable change in job conceptualisation and work practices by health personnel. It was not adopted in Somerset.

The authors acknowledge T O'Brien of Cow and Gate, whose encouragement and enthusiasm facilitated this study, but who died from breast carcinoma before its completion. This study was partly funded through an educational grant from Cow and Gate of Trowbridge, Wiltshire and the Somerset Health Authority.

1 Dearlove J. Abstracts not presented. In: Saffin K, ed. Where now? What next? The personal child health record. Proceedings of the national meeting 14 September 1994. Oxford: of the national meeting 14 September 1994. Oxford Community Health NHS Trust, 1994:102-4.

2 Dearlove J, Kearney D. How good is general practice develDearlove J, Kearney D. How good is general pract
opmental screening? BM7 1990;300:1177-80.

3 Morgan M, Evans M. Initiatives to improve childhood Morgan $M$, Evans $M$. Initiatives to improve childhood 1998;316:1569-70.

4 Kitzman H, Olds DC, Henderson CR, et al. The effect of prenatal and infancy home visitation by nurses on pregnancy outcomes, childbirth injuries, and repeated childbearing. FAMA 1997;278:644-52.

5 Bero L, Grilli R, Grimshaw M, et al. Closing the gap between research and practice: an overview of systematic reviews of interventions to promote the implementation of research findings. $B M \mathcal{F} 1998 ; 317: 465-8$.

6 Darbyshire P, Morrison H. Empowering parents of children with special needs. Nurs Times 1995;32:9-16.

7 Sheldon T, Wilson P, Tourner Boutle M, Sharp F. Hearing screening. In: Sheldon T, Wilson P, et al, eds. Effective health care: speech, language and vision screening. NHS Centre for Reviews and Dissemination, University of York Publishers, FT Healthcare, 1998:3-5.

8 Appleton P, Boll V, Everett J. Beyond child development centres: care coordination for children with disabilities. Child Care Health Dev 1997;23:29-40.

9 Irigoyen M, Findley S. Methodological difficulties in assessing contributions by community based organisations to improving child health. Arch Pediatr Adolesc Med 1998;152: 318-19.

10 Scott S. Intensive interventions to improve parenting. Arch Dis Child 1998;79:90-3.

11 Reading R, Allen C. The impact of social inequalities in child health on health visitors work. Fournal of Public Health 1997; 19:424-30.

12 Lewin $\mathrm{K}$. The group reason and social change. In: Magoby $\mathrm{E}$, ed. Readings in social psychology. London: Holt, Einston, 1958.

13 Ottaway R. A change strategy to implement new norms new style and new environments in the work organisation. style and new environments
Personnel Review 1976;5:13-15.

14 Whitehead M. Studies with a behavioural focus. In: Benzejal M, Judge K, Whitehead K, eds. Tackling inequalities in health: an agenda for action. London: Kings Fund, 1995:31-3.

15 Appleton P, Minchom P. Models of parent partnership and child development centres. Child Care Health Dev 1991;17: 27-38.

16 Kendall J. Fighting back. Promoting emancipatory nursing actions. Advances in Nursing Science 1992;15:1-15.

17 Wremann C, DuBois J, Berenson A. Strategies to promote breast feeding amongst adolescent mothers. Arch Pediatr Adolesc Med 1998;152:862-9.

18 Locklin M. Telling the world: low income women and their breast feeding experiences. F Hum Lact 1995;11:285-91.

19 Oliver S, Rajan L, Turner H, et al. Informed choice for users of health services: views on ultrasonography leaflets of women in early pregnancy, midwives and ultrasonograwomen in early pregnancy, mid

20 Praill T, Baldwin S. Beyond hero-innovation: real change in unreal systems. Behavioural Psychotherapy 1988;16:1-14.

21 Wright S. Changing nurse practice. London: Edward Arnold, 1998.

22 Williams D. Vulnerable families: a study of health visitors prioritization of their work. Nurs Manage 1997;5:19-24.

23 Dolan B, Kitson A. Future imperatives: developing health visiting in response to changing demands. F Clin Nurs 1997;6:11-16 